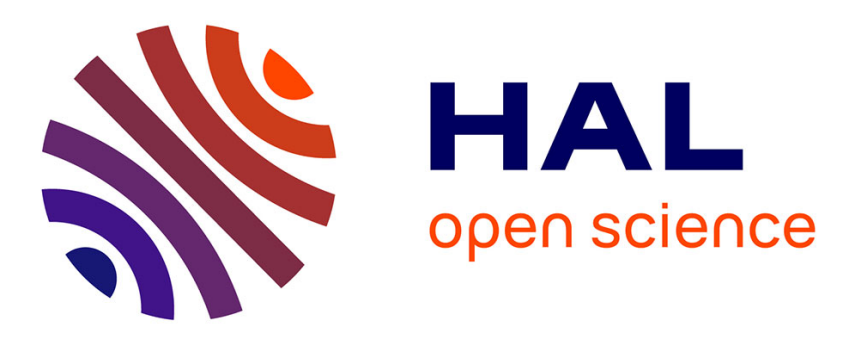

\title{
Traces of dispersion: online media and diasporic identities
}

Dana Diminescu, Benjamin Loveluck

\section{To cite this version:}

Dana Diminescu, Benjamin Loveluck. Traces of dispersion: online media and diasporic identities. Crossings: Journal of Migration \& Culture, 2014, 5 (1), pp.23-39. 10.1386/cjmc.5.1.23_1 . halshs01172505

\section{HAL Id: halshs-01172505 https://shs.hal.science/halshs-01172505}

Submitted on 7 Jul 2015

HAL is a multi-disciplinary open access archive for the deposit and dissemination of scientific research documents, whether they are published or not. The documents may come from teaching and research institutions in France or abroad, or from public or private research centers.
L'archive ouverte pluridisciplinaire HAL, est destinée au dépôt et à la diffusion de documents scientifiques de niveau recherche, publiés ou non, émanant des établissements d'enseignement et de recherche français ou étrangers, des laboratoires publics ou privés. 


\title{
Traces of dispersion. Online media and diasporic identities
}

\author{
Dana Diminescu \& Benjamin Loveluck
}

FINAL DRAFT

Published in Crossings: Journal of Migration \& Culture vol. 5, $\mathrm{n}^{\circ}$ 1, 2014, pp. 23-39

\begin{abstract}
:
Drawing mainly on the e-Diasporas Atlas project (www.e-diasporas.fr), this article seeks to understand how the Web has affected diasporic self-representations. More specifically, by engaging with both media theory and migration studies, it addresses the new modes of boundary formations that arise in the context of migration flows, and how these are mediated by the Web. It sheds light on two main levels of online diasporic identity-building. The first can be situated firmly within a paradigm of 'graphic reason', and relates to the sociosemiotic traces documented on diasporic websites. The second examines traces of another kind, which are formed by the hyperlinked networks of e-Diasporas on the Web, and which can be situated within a paradigm of 'digital reason'. Some of the consequences for diasporic identity-formation are drawn out, particularly issues relating to strategies of visibility on the Web.
\end{abstract}

\section{Keywords:}

Diasporas; e-Diasporas; Identity; Traces; Networks; Web science; Digital methods

\section{The connected migrant: from migratory trajectories to migratory traceabilities}

All aspects of the migrant experience are affected by the ubiquitous presence of digital technologies. Even before $\mathrm{s} /$ he has left, the would-be migrant now usually forms her/his project after a thorough search on Google, rather than after hearing the stories told by those who have returned from emigration. Before crossing any geographical borders, the voyage often involves going 'through the screen' - crossing an informational frontier made up of databases and identification systems, such as the Schengen Information System (SIS) throughout Europe. Upon arrival in a new country, one of the first necessities is to acquire a mobile phone and maybe gain access to a computer, in order to find work but also to 'remain connected' with family and friends wherever they are.

Such phenomena have informed our research for over a decade, leading us to situate migrants firmly within the paradigm of 'connected presence' (Licoppe 2004). Our understanding of the migrant experience has therefore changed: it can no longer be understood as a case of 'double absence' (Sayad 2004), but needs to be grasped rather as a logic of multiple forms of presence, associated with the connected migrant (Diminescu 2008; Diminescu 2010). The diversity of communication channels enables migrants to maintain 
frequent ties with the country of origin, whilst at the same time building relationships within the host country. In effect, migrants are therefore straddling two or several socio-cultural spaces, which in turn leads them to form hybrid identities in an on-going, complex process of cross-fertilisation, of shifting balances of power within the self, and of fluctuating relationships with various communities.

In particular, conversations via Skype, interactions via email and social media platforms such as Facebook, RenRen or VKontakte, and the access to information on websites have had a profound bearing on the daily lives of migrants, who have established novel ways of living together at a distance, rather than sharing only the sporadic moments of communication previously associated with letter-writing and expensive phone calls. Recent fieldwork, which includes qualitative interviews and ethnographic observation carried out in the context of the Mig@Net European project (Diminescu 2012c), the European Commission JRC (Diminescu et al. 2010), and the Research Chair on Social Networks of the Institut Mines-Telecom (Paris), has helped us understand how information and communication technologies provide ways and means of satisfying a 'compulsion of proximity' - whereby migrants feel the need to bridge the distance separating them from those they have left behind. Such changes have alleviated many constraints which previously weighed upon migrant populations. However, they also carry strong implications for identity formation in this context - of what it means to be a migrant today.

Addressing such issues has involved delving deeper into the mechanisms of community formation and self-representation within the digital environment, and has also called for a conceptual and methodological overhaul. Indeed, it has been necessary to focus our attention not only on migratory trajectories, but also to seize what could be called migratory traceabilities. In the case of trajectories, the movements of individuals and groups from point A to point B are assessed - and their meanings uncovered - say through demographical data and statistics, and through individual interviews. In the case of traceabilities, an additional effort is made to understand the complex information flows and the networks woven through daily interactions with the country of origin, with the host country, and with other members of the diaspora. Thus, our research has hinged both on in-depth interviews and on the study of the multiple traces left by migrant activity within the digital environment: phone calls, email exchanges, video-communication technologies and recordings, Web browsing, posting on forums, as well as building profiles, updating statuses and actively networking on social media.

Such an approach borrows from what Carlo Ginzburg, originally writing about historiographical method, has called the 'evidential paradigm' as opposed to the 'Galileian paradigm' (Ginzburg 1989): it is the manifold details, in their singularity, which are the most effective way of characterising an event (such as attributions for a work of art based on pictorial marks) - as opposed to the event (or the painting) taken as a whole. Rather than attempting to identify an overall pattern from the outset, one examines the minute variations of very small pieces of evidence, like a detective on a crime scene, seeking forensic proofs such as fingerprints or hairs. Ginzburg tells us this paradigm, which relies on 'traces, symptoms, and clues', took shape in the nineteenth century but could go back to the human experiences of hunting and divination, and that 'this knowledge is characterized by the ability to construct from apparently insignificant experimental data a complex reality that could not be experienced directly' (Ginzburg 1989: 103). Such a 'conjectural' or 'semiotic' approach is an alternative to Galileian science taken as the quantification and repetition of phenomena (Ginzburg 1989: 106), and thus favours an effort towards reconstruction of interactions through the interpretation of traces, rather than a description and the search for regularities. 
This method seems particularly well suited to the digital environment. It carries obvious implications in terms of commercial as well as state surveillance, as the latest revelations about the methods used by the U.S. National Surveillance Agency have made clear. Indeed the possibilities which the evidential paradigm opens up for social control have been highlighted by Ginzburg himself (1989: 118-123), and other authors have stressed how technical mediation necessarily implies the production of new forms of evidence (Kittler 1999; Lauer 2011).

From a research perspective however, the evidential paradigm is a strong guiding principle, insofar as the object, such as forms and modes of organisation in a digital context, appears through a set of procedures and technical artefacts, which bring them to light. This has been the case for the e-Diasporas Atlas project, a study of diasporas on the Web relying on a combination of network analysis and sociological research, which set out to collect the small pieces of evidence left by hyperlinking practices, and to uncover their meaning. In this article, we would like to briefly present this research and argue that by concentrating on the traces left by hyperlinks over the Web, e-Diasporas has contributed to a shift in focus from 'graphical reason' to 'digital reason' when analysing contemporary diasporas. As such, it has shown how collective identity formation of migrant groups as mediated by the Web must account for structural dimensions of diasporic networks, and the increasingly strategic uses which can be made of digital traces.

\section{Traces of diasporas: the e-Diasporas Atlas}

Means of communication - travel and transport, letters, telephone etc. - and their role as 'technologies of presence' (Diminescu 2008; Milne 2010) have always been key to understanding diasporas (Elliott et al. 2006). Indeed, insofar as they both deal with the modalities and implications of 'presence at a distance', migration studies and media studies share common ground. Thus it should come as no surprise that diasporic activities over the Internet have already been the focus of a great deal of attention. Important contributions drawing on ethnographic research (Georgiou 2006), on a comparative analysis of websites based on interviews and investigation of discussion threads (Brinkerhoff 2009), on discourse analysis (Trandafoiu 2013) or on a variety of such methods (Alonso and Oiarzabal 2010) have already fleshed out crucial insights about diasporas in the new media environment. Identity formation, in this context, has been particularly scrutinized and generally appears as hybrid, layered and in constant (re)negotiation - thus entrenched in the transnationalist paradigm.

However, most of the studies devoted to 'digital diasporas' are mainly descriptive, importing tools and methodologies developed for offline phenomena, and concentrating on small samples of individual websites. Therefore, they fail to account for the main characteristic of the WWW: its networked nature, and the fact that websites occupy a position within this network, which has important consequences in terms of public visibility - and therefore the mediation of identity. In this article, we would like to suggest that the Web involves a radical departure in the way diasporas are formed, evolve, and represent themselves as diasporas - and that this change also calls for important epistemological and methodological innovations. The development of a large-scale migrant presence on the Web has generated huge amounts of data, leaving traces of all forms of online activity - such as website creation and management, blogging, or forum participation. Some of the most fascinating traces of this presence are the hyperlinks on the Web. These have been the focus 
of the e-Diasporas Atlas, which set out to explore the networks formed by diasporic websites. ${ }^{1}$ Over 80 researchers and engineers contributed to the project, in which diasporic networks were crawled, scraped, archived, visualized, mapped and analysed. ${ }^{2}$ This resulted in the creation of an extensive corpus of approximately 8,000 migrant websites, and the study of 30 diasporas on the Web. Moreover, as well as an archive of websites collected on a weekly or monthly basis over the past 4 years, the Atlas constitutes an open database which can be explored by anyone through a visualisation interface (http://maps.e-diasporas.fr). The project therefore continues to provide both a resource and a framework for future research - or for diasporic actors themselves, who might seek to gain an overarching vision and interpretation of their own traces.

The basic premise of the e-Diasporas Atlas is that studying diasporas should take seriously the proposition that we now live in a 'hyperlinked society' (Turow and Tsui 2008). The hyperlink, which consists both in an instrumental linkage and a social relation, lends itself to analyses of at least two orders, both technical and sociological. It has therefore been the focus of much attention, with the coming into being of a subfield of 'link studies' (Park 2003; de Maeyer 2013), itself drawing on the wider field of 'Web science' (Hendler 2008). Such studies have relied heavily on the 'new' science of networks (Watts 2004), which gives pride of place to graph theory and mathematics. However, they have also attempted to take the full measure of the sociological dimension of the hyperlink (Thelwall 2006).

Indeed, this allows for a different type of investigation, based on crawling and scraping the relational traces between a set of websites (Park 2003; Thelwall 2004). In this manner, relationships within a given population - e.g. bloggers, NGOs, or media portals - can be identified, since the links among websites provide the traces of the associations put in place by the actors themselves. Linking carries a meaning and can even be understood as a communicative strategy, insofar as actors signal their affiliation - or on the contrary try to avoid any such affiliation - with some other entity or actor. They may also try to enhance their visibility through associational effects. And above all, the general topology of the networks can be visualized and analysed, providing insights into characteristics of migrant populations that have been theorized, but not thus far studied systematically, such as their degree of cohesion, the bridging role played by certain actors etc.

However, an accurate collecting and interpreting of hyperlinks raises many technical and methodological issues (de Maeyer 2013). As such, the process cannot be automated and requires a hybrid approach, as advocated by Thelwall (2006). De Maeyer (2013: 748) also 'pleads for a systematization of (...) methods in a unified yet adaptive framework that would consist in combining quantitative link counts, qualitative inquiries and valuation of field expertise to support link interpretation', as has already been the case in a number of studies, especially those devoted to understanding networks of blogs (Hargittai et al 2008; Park \& Thelwall 2008).

Such a merging of qualitative fieldwork with topological network analysis has been a guiding principle for the e-Diasporas Atlas, as shown in its methodological framework

1 See www.e-diasporas.fr for further details, and for access to the working papers and the data. See also (Diminescu 2012a) and (Diminescu 2012b) for definitions and for a description of the methodology. e-Diasporas Atlas received funding from the French Agence Nationale de la Recherche (ANR), the Telecom ParisTech engineering school and the Fondation Maison des sciences de l'homme (FMSH), Paris.

2 The process involved the development of custom-built tools which have now been put to a wider use, such as Navicrawler (http://webatlas.fr/wp/navicrawler), a program for crawling the Web and collecting hyperlinks, and Gephi (https://gephi.org), a visualisation software. 
(Diminescu 2012b; Jacomy 2007). Thus the e-Diasporas project has provided ways and means to comprehensively collect and make sense of the traces left by the activities of migrant collectives and diasporic communities on the Web.

\section{Dimensions of diasporic identity on the Web}

It is now well known that interest for diasporas has seen a surge over the past few decades. Some authors have stressed the diversity of diasporic phenomena (Sheffer 1986). Their significance has been highlighted in the context of globalized late modernity and the development of transnational publics and imaginaries (Appadurai 1990; Tölölyan 1996), while their critical potential as heterogeneous and de-centered social forms has sometimes been emphasized (Hall 1990; Gilroy 1993; Clifford 1994). Indeed, the good fortune of the concept of diaspora, and the shift from negative to positive connotations, have been presented as a reflection of the changing significance of such political categories as the nation-state (Schnapper 2001). However, other authors have warned that a proliferation of the concept may dangerously stretch its meaning (Brubaker 2005), and thus many have attempted to establish criteria in order to make sense of the diverse forms of diasporic experience (Safran 1991; Cohen 2008).

Leaving aside the question of defining what a diaspora consists in, we are concerned here with the particular issue of diasporic identity, understood as diasporic self-definition. Indeed, although the notion of identity carries difficulties of its own, we would like to address it in a limited sense, which nevertheless brings forth a whole range of specific questions. As a first approximation, we take the formation of diasporic identities as involving that migrants recognize each other as being part of a dispersed collective, which is then more or less firmly established as a common project. The initial displacement leaves a mark, which is upheld as a strong feature of one's identity. For Emmanuel Ma Mung, referring to the Chinese example, diasporas are based on an (historical and geographical) origin from which dispersion has proceeded; awareness of both origin and dispersion, through the manifold representations of this experience, provide not only a continuity across time but also a shared space, where identity is projected and imagined together, and where dispersion remains a structural feature (Ma Mung 2012). Indeed, Ma Mung stresses that a diaspora is not simply a mere collection of individuals, but consists in a social form which is aware of its nature as a dispersed collective. He mentions Leibniz' distinction between an aggregate, which can be understood as the accidental coordination of social entities (unum per accidens), and a monad which is conscious of forming a whole and which is organized towards its self-preservation (unum per se). Thus for Ma Mung, a diaspora needs to create and recreate its specific 'spacetime', through a process of 'conversion': the common genealogy, for Ma Mung, is converted in a common topography.

The e-Diasporas Atlas has attempted to make sense of the very particular kind of topography drawn by hyperlinks on the World Wide Web. Through this approach, some specificities of diasporas as they are mediated through the Web can be grasped, providing valuable insights in the contemporary process of their identity formation. Indeed, the Web constitutes one of the main ways diasporas have been made manifest in recent years. It has provided a unique space for the enactment of diasporic activities, for mutual recognition of migrants as members of a diaspora, and for providing public visibility to diasporic formations. Through an examination of some of the material gathered for the e-Diasporas Atlas, we would like to argue that at least two levels of analysis can be identified to deal with the traces left by diasporas on the Web. 
The first level is inherent to what Jack Goody has called 'graphic reason' (Goody 1977), where traces are first and foremost of a written nature, constructing identity as a set of attributes remaining stable and recognisable across time and space (although always subject to being interpreted). The 'graphic reason' paradigm is still relevant on the Web - although the modalities of reading and writing are transformed in this context (Vandendorpe 2009). Indeed, at this level websites function as a repository for various forms of media - text, music, photos, videos etc. but also such items as databases of the population of a town in a given country at a given time. They therefore act as storage of traces - which, for migrants, can be associated with a common reference. They are a form of social semiotics, which can be analysed through the content on display, the associated discourses and representations, and the ways in which markers of a specific cultural tradition are upheld: signs, writings, religious icons, culinary practices, dressing habits etc. Websites, from this perspective, act as mirrors of a given (real, reconstructed, or imagined) tradition - i.e., of the distinctive elements of the diasporic group. These have been the focus of most of the existing work on 'digital diasporas' mentioned above.

The second level, however, can be seen as pertaining to 'digital reason', whereby identity can be reconstructed as the unique sum of traces left behind by a given activity or set of activities. At this level, websites generate traces in and of themselves: the traces formed by the hyperlinks which point from one website to the next. Like any other trace, hyperlinks both display some meaning (connections), and leave out what cannot be encompassed by hyperlinks. These traces, however, are not random, but are set up with a certain purpose in mind. Thus they form what could be called an associational dynamics - a characteristic which has long been recognized as providing a certain type of 'order' to the Web as made up of clusters, hubs and authorities (Gibson et al 1998; Kleinberg and Lawrence 2001), and which has been leveraged by the likes of Google for instance. More generally, the communities formed by such a space of traces are highly dependant on structural constraints and affordances of the Web as a socio-technical apparatus, which provide it with recognisable shapes.

From this perspective, one must also take into account the strategies involved in linking with certain websites, or in avoiding any association with certain other websites. These can be revealed through the e-Diasporas Atlas, which combines graph analysis and qualitative assessment of websites. Moreover, we would contend that the visualisations and interpretations of the networks formed by e-Diasporas are a step in the direction of increasing self-awareness of diasporas on the web, which increasingly adopt a more reflexive stance: the different actors are more and more conscious of each other's place in an overall network of Web connections, and take steps to shape the profile of their website or set of websites accordingly.

\section{Web-based diasporic identities: from self-expression to strategies of visibility}

Several examples will serve as illustration. In the specific case of Europe, analysis of diasporas on the Web sheds new light on the many underlying forces which are shaping it today - the multiple feelings of cultural belonging which should be taken into account, whether they are considered legitimate or not. These include for instance: the forms of 'memorial activism' undertaken by French repatriates in a postcolonial context, who have left the territories which were formerly under French colonial rule (Scioldo-Zürcher 2012); the construction of a diaspora at the same time as the founding of a new nation-state such as Macedonia (Balalovska 2012); and the surviving of a Yugoslav cultural sphere despite the 
disappearance of Yugoslavia as a nation-state, and its interaction with the 'new' national identities after the break-up (Mazzucchelli 2012). ${ }^{3}$

If we focus on the Yugoslav case, we observe that 'Yugonostalgia' understood as a yearning for the disappeared country, drives projections on the Web which have already been analysed in terms of repositories of collective memories. A decade ago Mikula 2003, for instance, looked at two websites (one devoted to the 'virtual nation' of 'Cyber-Yugoslavia', and one devoted to former Yugoslav president Tito: www.titoville.com), and highlighted the use of parody to express a 'repressed collective memory' of 'South Slav unity' (see Figure 1). In this perspective, websites were analysed in terms of their socio-semiotic signification as 'virtual archives' (Mikula 2003: 171) and the parodic, 'carnivalesque' play on cultural references, ${ }^{4}$ in a context where 'cyberspace' was presented as 'challeng[ing] the divisive ethno-nationalist rhetoric, prominent especially in the early 1990s' (Mikula 2003: 170).

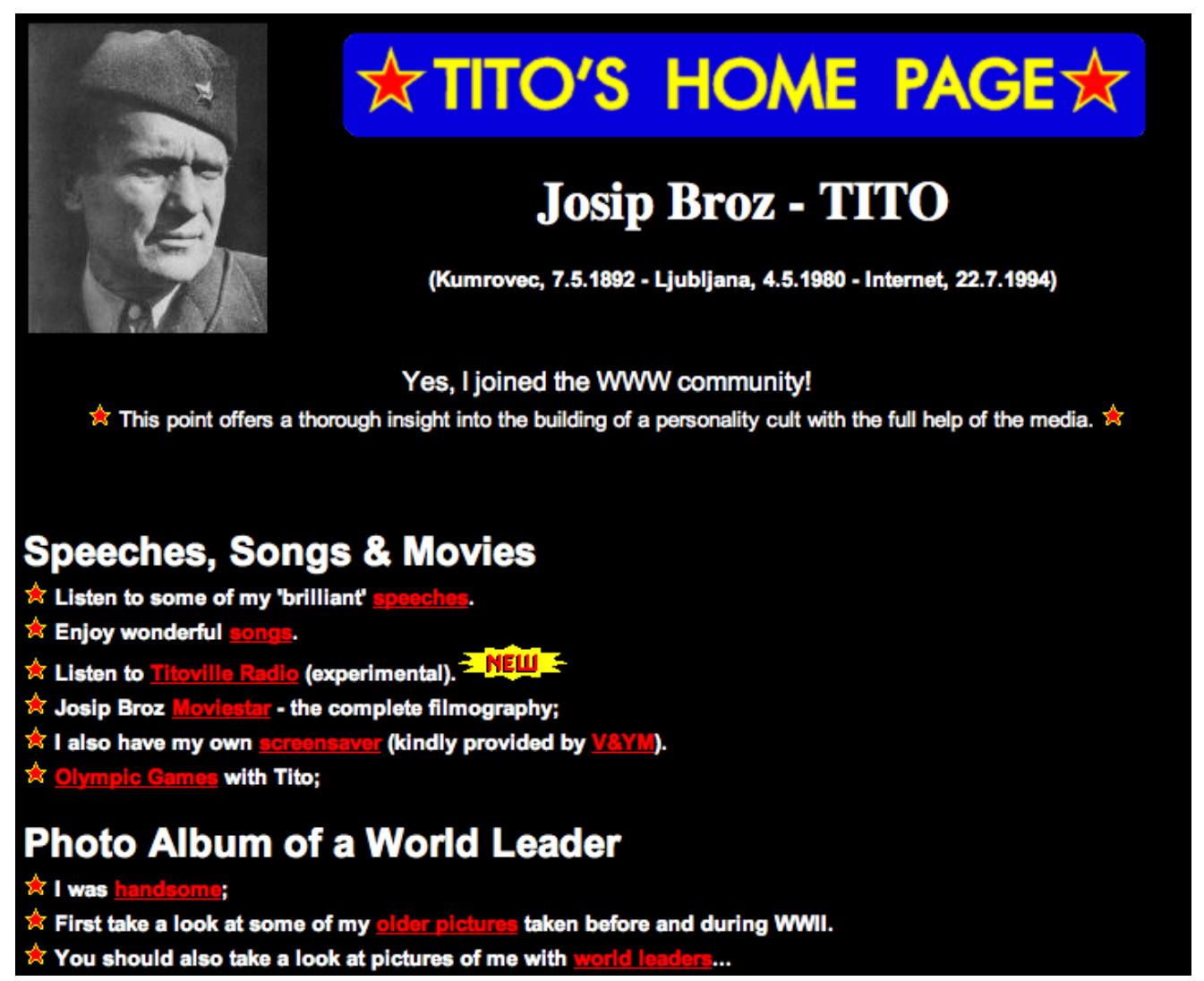

Figure 1: www.titoville.com, screen capture, 31 July 2013.

3 See also http://www.e-diasporas.fr/wp/scioldo-zurcher.html; $\quad$ http://www.ediasporas.fr/wp/balalovska.html; and http://www.e-diasporas.fr/wp/mazzucchelli.html for access to the working papers and data.

4 'Parody in Cyber-Yugoslavia focuses on a number of fundamental building blocks of any national narrative: its iconography, sites of memory and forgetting, mental calendars and geographies, rationalizations of power mechanisms within the state and eschatological projections for the imagined community. In the not so distant past, the parodied texts were legitimate symbols of former- Yugoslav national lore.' (Mikula 2003: 173-174); as for the Tito homepage: 'It is written in the first person, with the deceased leader announcing his symbolic 'revival' in cyberspace and promising to offer a 'thorough insight into the building of a personality cult with the full help of the media'.' (Mikula 2003: 180-181). 
Ten years later Francesco Mazzuchelli, in the e-Diasporas project, sought to go further and to "map the Yugoslav ideal community through the traces left by them in "cyberspace" (2012: 638) - with the added twist that, although Yugoslavia broke up in 1991 and formally ceased to exist in 2003, the Yugoslav top-level domain name (.yu) was only removed in 2009 by ICANN. The crawl used for e-Diasporas enables to go beyond a focus on one or several websites, and to build a more comprehensive corpus which can then be coded (in terms of language, content, geographical location etc.) and provide statistical data on what can now be presented as a Web 'Yugosphere'. Moreover, it also provides an overall topology of this sphere and displays its centre and peripheries, regroupings and intersections, sub-communities and 'archipelagos' of lone websites. Not only is the www.titoville.com website still up and running, but it has acquired a central role - along with several other authorities - within a wider Web ecology which we are now better able to understand (see Figure 2). Different clusters can be pinpointed, along with their positions relative to one another: Mazzuchelli identifies 'socialist nostalgic websites; pop Yugoslav websites 'playing' with the 'figurative grammars' of the Yugoslav repertoires and recombining its languages in a pop-culture version; retro-Yugoslav websites, that 'pretend not to notice' that Yugoslavia has faded away; and eventually post-Yugoslav websites, whose users wander the Web looking for a digital version of that 'common space' they have lost in the geo-political world' (2012: 645).

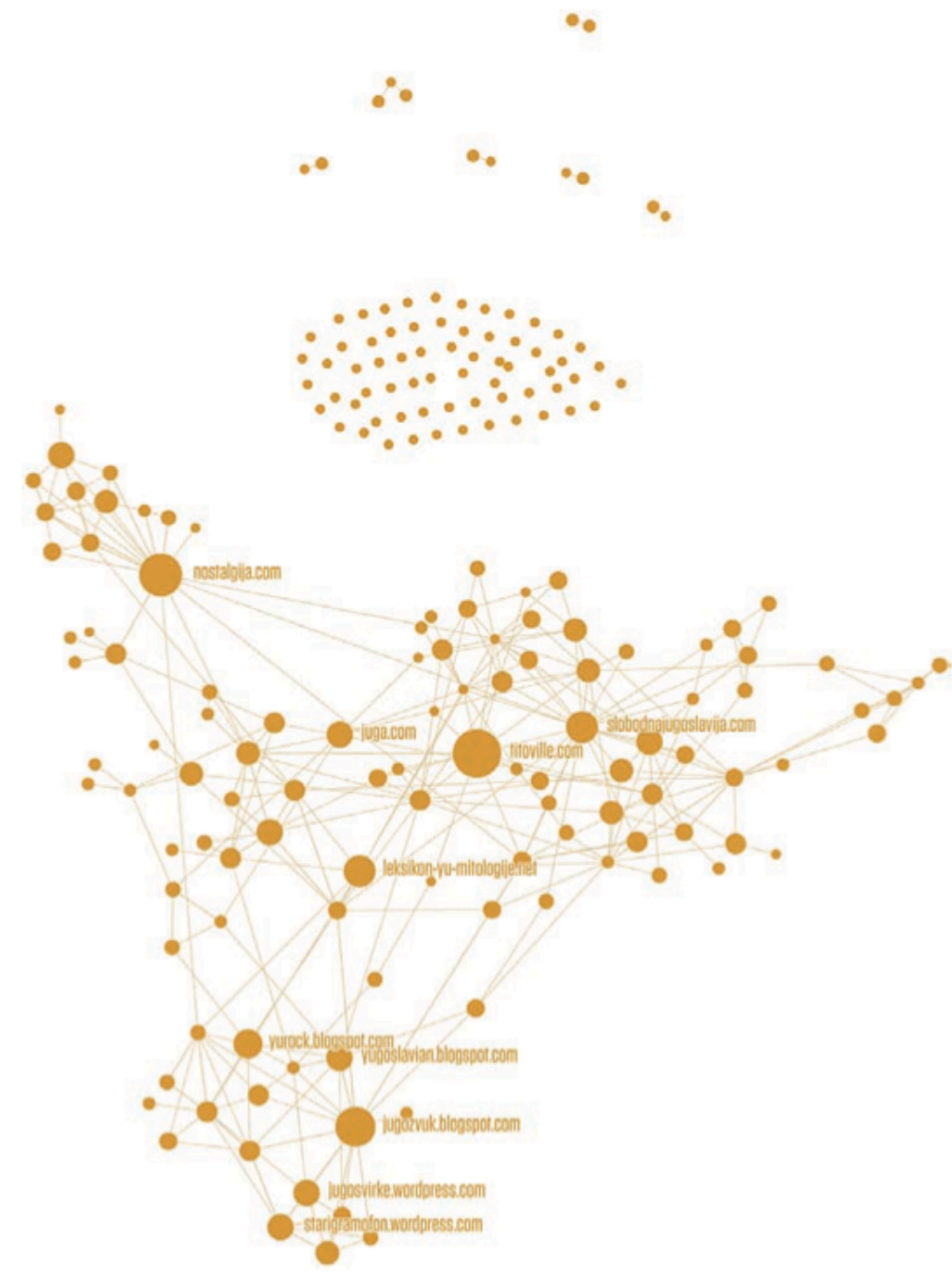

Figure 2: The Web 'Yugosphere', Mazzuchelli 2012. 
Likewise, another telling example is the case of French colonial repatriates websites analysed by Yann Scioldo-Zürcher (2012). A textual and semiotic analysis first highlights the motivations behind such websites which, as diasporic identifications, are also spurred by a feeling of 'loss' and nostalgia - a yearning or 'melancholia' for France's imperial past, also put forward in the British case by Paul Gilroy (2004). They are classified by the author, who describes them as ranging from straightforward memorial issues articulated around the documentation of cultural aspects (such as photos, songs, religious symbols, culinary traditions etc.), to the political expression of mainly right-wing ideologies associated with the end of colonial power and fuelling xenophobic sentiments - with the two sometimes interacting in complex ways, and also presenting a very specific relationship to the French state and institutional/governmental websites. Scioldo-Zürcher thus notes that: 'Since the distinction between memory and politics is blurred, it is initially through a reading of the symbolic 'meta-language' used that we are able to grasp the political leanings of the various websites' (2012: 490). He thus shows how a website such as http://tournantsrovigo.free.fr, while initially seeming to be a digital trip down the memory lanes of a specific area in Algiers (see Figure 3), after closer inspection turns out to be conveying a positive image of colonisation and a political leaning associated with 'Algérie française'.

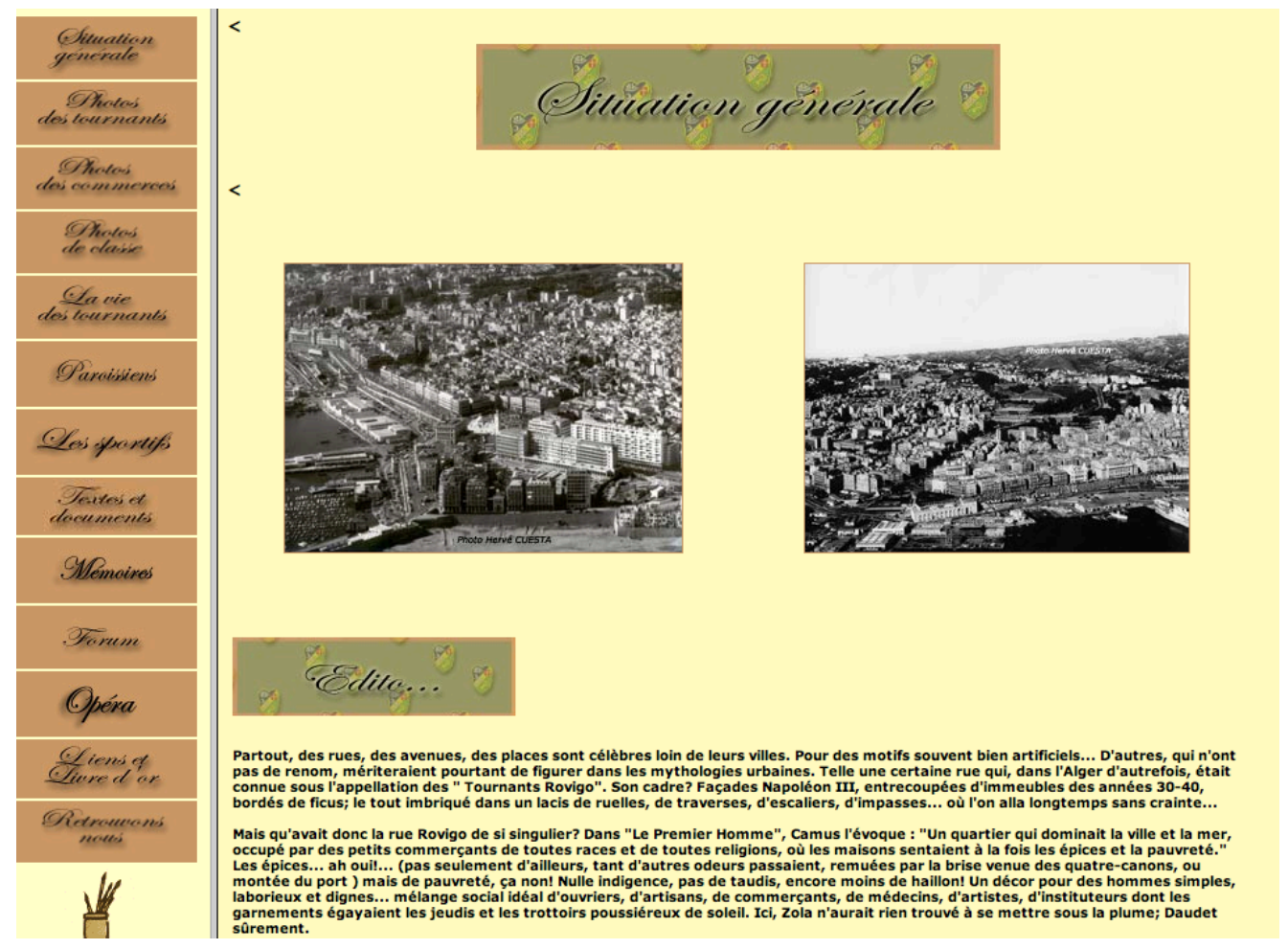

Figure 3: http://tournantsrovigo.free.fr/, screen capture, 31 July 2013.

However, the author goes on to say that this approach must be complemented by network analysis since 'the full nature of the website is revealed through its associated network' (ibid.). In particular, the latent political leanings of sets of websites can be further explored in this way (see Figure 4). 


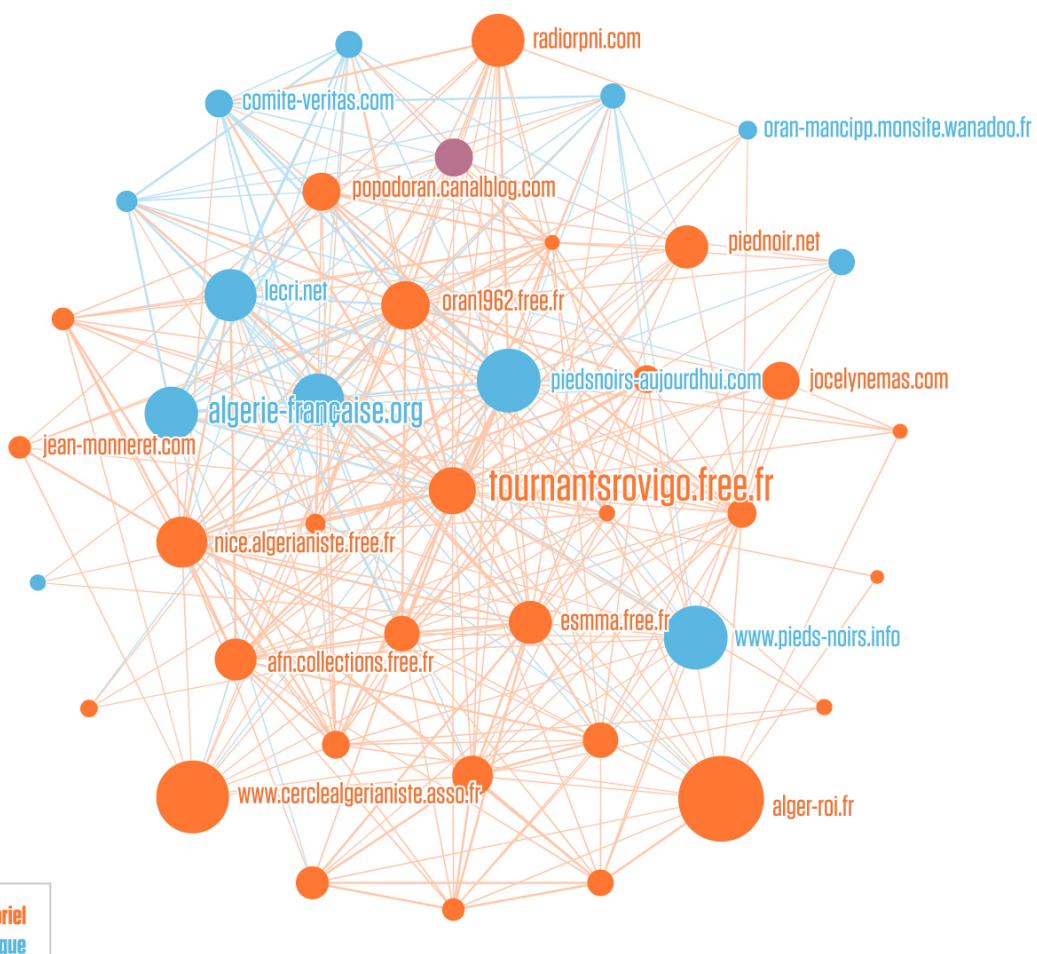

Figure 4: French colonial repatriates e-Diaspora, Sciolodo-Zürcher 2012. Location in the corpus of the http://tournantsrovigo.free.fr website (detail).

Scioldo-Zürcher also demonstrates the overall failure to mobilize the repatriate community effectively (with many websites set up by individuals and decoupled from existing 'real life' associations), which show that the presumed influence of colonial repatriates in French political life is in fact largely over-stated.

In certain contexts, the e-Diasporas methodology can shed more specific light on the strategic uses of diasporic identity - as demonstrated, for instance, in the study carried out by Ingrid Therwarth (2012) on Indian diasporic websites. At first glance, a website such as www.SaveTemples.org, which is part of her corpus, has been set up by the Global Hindu Heritage Foundation based in Texas, USA, and seeks to federate Indian Hindus around the preservation of temples (see Figure 5).

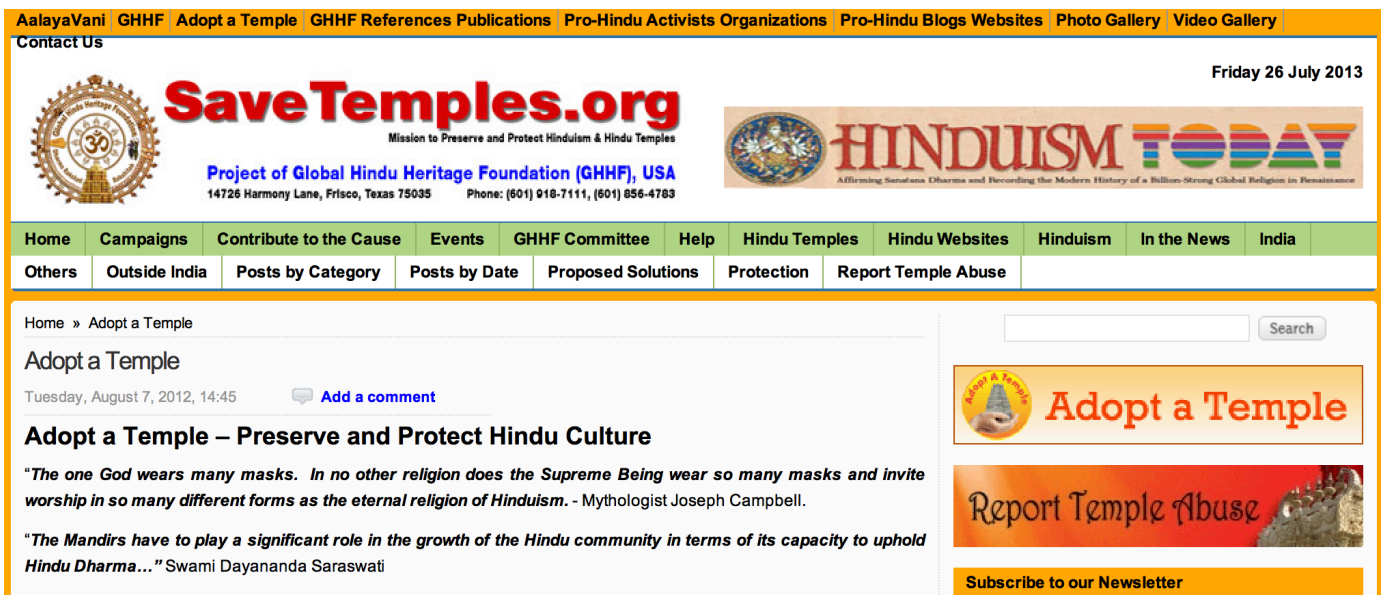

Figure 5: www.SaveTemples.org, screen capture, 26 July 2013. 
A more informed reading will situate this website in the context of Hindu nationalism. However, only a thorough examination of web traces may reveal the place of this website within the general topography of 'long-distance' Hindu nationalism on the Web (see Figures 6 and 7). Such an exploration leads to the more complex picture presented by Therwarth:

The hindutva groups, very ideologically attached to the Indian territory, operate institutionally from the United States and are maintained by an elite, composed of conservative men close to extremist Jewish groups with whom they share Islamophobic views. The analysis of 'spaces', 'gaps' or 'blanks' in the corpus completes this reading and brings to light strategies of avoidance, circumvention and discretion that lead to a considerable morphological difference between the online and the offline network. Legal and reputational restrictions explain this dissonance. The different audiences targeted - community audiences, generalist audiences and local authorities - should be made aware of this.

(Therwarth 2012: 572)

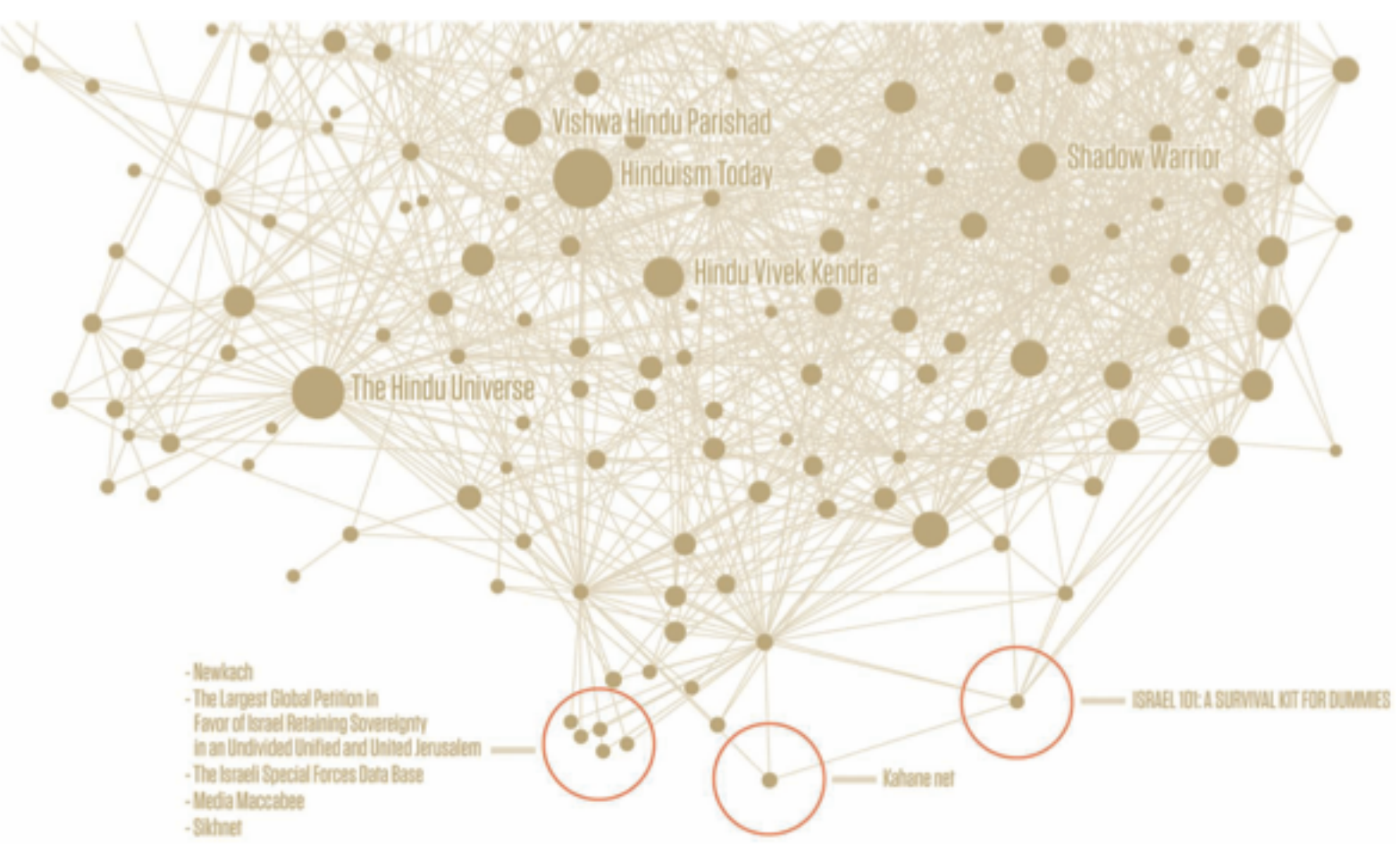

Figure 6: Hindutva e-Diaspora, Therwarth 2012. Links between extremist Jews and extremist Hindus in diaspora in the USA. 

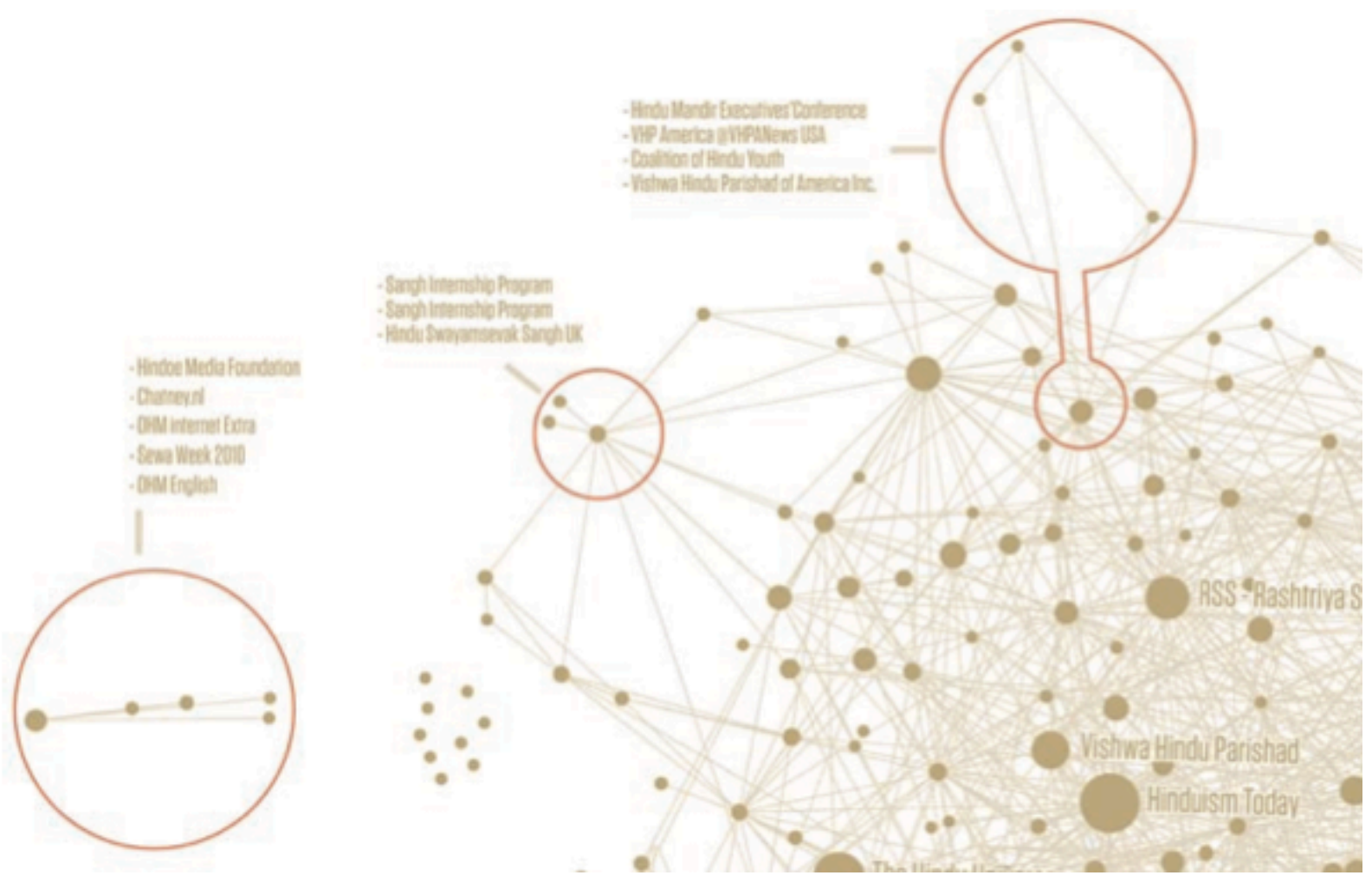

Figure 7: Hindutva e-Diaspora, Thewarth 2012. The blanks of the hindutva network.

\section{Conclusion: identity formation and strategies of visibility on the Web}

Of course, the e-Diasporas approach leaves out certain dimensions of social activity online such as communication channels (IRCs, Skype) and social media - in particular Facebook, which to a large extent forms a closed 'Web within the Web' due to its proprietary standards, and cannot be mapped in the same way. We have not mentioned here, either, how many diasporic websites function as forums and thus as nodes of socialisation and interaction between individuals. As such, it provides a partial view of digital diasporic activities - and indeed, an e-Diaspora should never be mistaken for the diaspora itself. It is a representation of the diasporic experience, a set of projections which leave a trace and which shape diasporic identity - and these can only be partial, insofar as they are mediated.

Our contention in this article, however, is that these digital traces shape identity in a unique way, and give a potent access to the contemporary workings of diasporic identity formation, in a context where 'digital reason' is gradually supplementing 'graphic reason'. 'Traditional' semiotic markers of identity are still very much a component of this process, and many websites function as repositories and mirrors of the texts, pictures, sounds of the traditions which make up the singular but shared experiences towards which diasporas look back. However, in order to know if a diaspora has gained some 'actuality' online, network analysis must be summoned. It then becomes possible to observe if, through the media, not only transmission of a culture but active participation in this culture is taking place. Further

\footnotetext{
A situation decried by the World Wide Web's 'founding father', Tim Berners-Lee, for whom 'The more this kind of architecture gains widespread use, the more the Web becomes fragmented, and the less we enjoy a single, universal information space' (Berners-Lee 2010). From a research perspective, this raises important issues concerning the limits of a 'Web science' (Hendler 2008), in a context where data will increasingly be generated on privately held, closed platforms.
} 
improvements should strive to include on-going developments in Web usage, and put increasing onus on social platforms, mobile use and geolocation. ${ }^{6}$

Indeed, e-Diasporas should be approached as forms of 'networked publics' (Varnelis 2008; boyd 2010), which 'emerge' and to some extent self-organize through digital activity and its aggregation in the form of networks. They are thus attuned to the contemporary context of 'informational liberalism' and the different modes of self-organisation it fosters (Loveluck 2012), as well as being in phase with the unstable, distributed nature of migrant collectives. Within such 'communities', the sense of belonging can be more or less strong, more or less politically oriented - and can be observed and analysed as such through traditional interpretative methods. However, the mapping and visualisation of online diasporic networks further demonstrates in what sense e-Diasporas can also be understood as productive and strategic endeavours. The shape of the network, and the type of visibility which is derived from it, enable certain actors to 'speak for' and to orient the self-presentation of a diaspora. The Atlas helps to reveal such strategies and to make explicit diasporic representations, which are founded first and foremost on the link and on projections on the Web rather than on the general relationship to a given territory.

This echoes more general, heuristic attempts to characterize some groups as diasporas in order to actually bring these diasporas into being, to gain recognition and maybe to raise a certain number of issues (Dufoix 2011: 448-459) - as has been the case, most notoriously, with the 'Black' or 'African' diaspora (Dufoix 2011: 485-492), with the risk of excessive uniformity in depicting the diversity of historical experiences. The tools and methodologies developed in the context of the e-Diasporas Atlas help researchers to acknowledge such a reflexive appropriation of the notion of diaspora by the actors themselves. At the same time, it also provides them with the means to go beyond homogenizing pictures and to uncover the strategic uses to which the idea of diaspora can be put. We hope that such a research path will be further refined and will lead to other fruitful results.

\section{Bibliography}

Alonso, A. and Oiarzabal, P.J. (eds) (2010), Diasporas in the New Media Age. Identity, Politics, and Community, Reno, NV: University of Nevada Press.

Appadurai, A. (1990), 'Disjuncture and difference in the global cultural economy', Theory, Culture \& Society, 7: 2, pp. 295-310.

Berners-Lee, T. (2010), 'Long live the Web: a call for continued open standards and neutrality', Scientific American, December [http://www.scientificamerican.com/article.cfm?id=long-live-the-web, accessed 5 August 2012]

Balalovska, K. (2012), 'Discovering the Macedonian diaspora: a Web cartography of actors, interactions and influences', Social Science Information, 51: 4, pp. 611-630.

boyd, d.m. (2010), 'Social network sites as networked publics: affordances, dynamics, and implications', in Z. Papacharissi, (ed.), A Networked Self. Identity, Community, and Culture on Social Network Sites, New York and London: Routledge, pp. 39-58.

6 One area of further research, for instance, would be to examine the deployment of e-Diasporas in the context of the increasing national biases built into the Web, and to engage with what Richard Rogers has proposed to call ‘National Web studies' (Rogers 2013). 
Brinkerhoff, J.M. (2009), Digital Diasporas. Identity and Transnational Engagement, Cambridge and New York: Cambridge University Press.

Brubaker, R. (2005), 'The 'diaspora' diaspora', Ethnic and Racial Studies, 28: 1, pp. 1-19.

Clifford, J. (1994), 'Diasporas', Cultural Anthropology, 9: 3, pp. 302-338.

Cohen, R. (2008), Global Diasporas. An Introduction, 2nd revised edition, London and New York: Routledge.

Diminescu, D. (2008), 'The connected migrant: an epistemological manifesto', Social Science Information, 47: 4, pp. 565-579.

Diminescu, D. (2010), 'Présentation du dossier : les migrants connectés. TIC, mobilités et migrations', Réseaux 159, pp. 9-13.

Diminescu, D., Jacomy, M. and Renault, M. (2010), Study on Social Computing and Immigrants and Ethnic Minorities: Usage Trends and Implications, European Commission Joint Research Centre, Institute for Prospective Technological Studies, February.

Diminescu, D. (ed) (2012a), e-Diasporas Atlas. Explorations and Cartography of Diasporas on Digital Networks, Paris: Ed. de la Maison des Sciences de l'Homme.

Diminescu, D. (2012b), 'Introduction: digital methods for the exploration, analysis and mapping of e-diasporas', Social Science Information, 51: 4, pp. 451-458.

Diminescu, D. (ed) (2012c), Here, There and (Almost) Now. How ICTs Transform Migrants' Living at Home, thematic report on Information \& Communication Flows, Mig@Net European project on Transnational Digital Networks, Migrations and Gender, October.

Dufoix, S. (2011), La Dispersion. Une histoire des usages du mot diaspora, Paris: Ed. Amsterdam.

Elliott, B.S., Gerber, D.A. and Sinke, S.M. (eds) (2006), Letters Across Borders. The Epistolary Practices of International Migrants, New York and Basingstoke: Palgrave Macmillan.

Georgiou, M. (2006), Diaspora, Identity and the Media. Diasporic Transnationalism and Mediated Spatialities, Creskill, NJ: Hampton Press.

Gibson, D., Kleinberg, J. and Raghavan, P. (1998), 'Inferring web communities from link topology', in Proceedings of the 9th ACM Conference on Hypertext and Hypermedia, New York: ACM, pp. 225-234.

Gilroy, P. (1993), The Black Atlantic. Modernity and Double Consciousness, Cambridge, MA: Harvard University Press.

Gilroy, P. (2004), After Empire. Melancholia or Convivial Culture?, London and New York: Routledge. 
Ginzburg, C. (1989), 'Clues. Roots of an evidential paradigm', in Clues, Myths, and the Historical Method, Baltimore, MD: Johns Hopkins University Press, pp. 96-125.

Goody, J. (1977), The Domestication of the Savage Mind, Cambridge University Press: Cambridge and New York.

Hall, S. (1990), 'Cultural identity and diaspora', in J. Rutherford (ed.), Identity. Community, Culture, Difference, London: Lawrence and Wishart, pp. 222-237.

Hargittai, E., Gallo, J. and Kane, M. (2008), 'Cross-ideological discussions among conservative and liberal bloggers', Public Choice, 134: 1-2, pp. 67-86.

Hendler, J., Shadbolt, N., Hall, W., Berners-Lee, T. and Weitzner, D. (2008), 'Web science: an interdisciplinary approach to understanding the Web', Communications of the ACM 51: 7, pp. 60-69.

Jacomy, M. and Ghitalla, F. (2007), Méthodologies d'analyse de corpus en sciences humaines à l'aide du Navicrawler. Rapport final, Paris: Fondation de la Maison des Sciences de l'Homme, August.

Kittler, F. (1999), Gramophone, Film, Typewriter, Stanford, CA: Stanford University Press.

Kleinberg, J. and Lawrence, S. (2001), 'The structure of the Web', Science, 294, pp. 18491850 .

Lauer, J. (2012), 'Surveillance history and the history of new media: an evidential paradigm', New Media \& Society, 14: 4, pp. 566-582.

Licoppe, C. (2004), 'Connected presence: the emergence of a new repertoire for managing social relationships in a changing communication technoscape', Environment and Planning D: Society and Space, 22, pp. 135-156.

Loveluck, B. (2012), 'La liberté par l'information. Généalogie politique du libéralisme informationnel et des formes de l'auto-organisation sur Internet', $\mathrm{PhD}$ thesis, Paris: École des Hautes Études en Sciences Sociales.

de Maeyer, J. (2013), 'Towards a hyperlinked society: a critical review of link studies', New Media \& Society, 15: 5, pp. 737-751.

Ma Mung, E. (2012), 'Continuité temporelle, contiguïté spatiale et création d'un mondepropre. Le cas de la diaspora chinoise', L'Espace géographique, 41: 4, pp. 352-368.

Mazzucchelli, F. (2012), 'What remains of Yugoslavia? From the geopolitical space of Yugoslavia to the virtual space of the Web Yugosphere', Social Science Information, 51: 4, pp. 631-648.

Mikula, M. (2003), 'Virtual landscapes of memory', Information, Communication \& Society, 6: 2, pp. 169-186.

Milne, E. (2010), Letters, Postcards, Email. Technologies of Presence, New York: Routledge. 
Park, H.W. (2003), 'Hyperlink network analysis: a new method for the study of social structure on the Web', Connections, 25: 1, pp. 49-61.

Park, H.W. and Thelwall, M. (2008), 'Developing network indicators for ideological landscapes from the political blogosphere in South Korea', Journal of Computer-Mediated Communication, 13: 4, pp. 856-879.

Rogers, R. (2013), 'Ch. 6 - National Web studies', in Digital Methods, Cambridge, MA: MIT Press, pp. 125-151.

Safran, W. (1991), 'Diasporas in modern societies: myths of homeland and return', Diaspora: A Journal of Transnational Studies, 1: 1, pp. 83-99.

Sayad, A. (2004), The Suffering of the Immigrant, Cambridge and Malden, MA: Polity.

Schnapper, D. (2001), 'De l'Etat-nation au monde transnational. Du sens et de l'utilité du concept de diaspora', Revue Européenne des Migrations Internationales, 17: 2, pp. 9-36.

Scioldo-Zürcher, Y. (2012), 'Memory and influence on the Web: French colonial repatriates from 1950 to the present', Social Science Information, 51: 4, pp. 475-501.

Sheffer, G. ed. (1986), Modern Diasporas in International Politics, London: Croom Helm.

Thelwall, M. (2004), Link Analysis. An Information Science Approach, Amsterdam: Elsevier Academic Press.

Thelwall, M. (2006), 'Interpreting social science link analysis research: a theoretical framework', Journal of the American Society for Information Science and Technology, 57: 1, pp. 60-68.

Tölölyan, K. (1996), 'Rethinking diaspora(s): stateless power in the transnational moment', Diaspora: A Journal of Transnational Studies, 5: 1, pp. 3-36.

Trandafoiu, R. (2013), Diaspora Online. Identity Politics and Romanian Migrants, New York and Oxford: Berghahn.

Turow, J. and Tsui, L. (eds) (2008), The Hyperlinked Society. Questioning Connections in the Digital Age, Ann Arbor, MI: University of Michigan Press.

Vandendorpe, C. (2009), From Papyrus to Hypertext. Toward the Universal Digital Library, Urbana, IL: University of Illinois Press.

Varnelis, K. (ed) (2008), Networked Publics, Cambridge, MA and London: MIT Press.

Watts, D.J. (2004), 'The “new” science of networks', Annual Review of Sociology, 30, pp. 243-270. 